\title{
Situating the 'Crisis of Representation' in Ethnographic Approaches to Theology and Working Toward Community-Centered, Dialogic Approaches
}

\author{
Kristy Nabhan-Warren \\ Ph.D, Professor and V.O. and Elizabeth Kahl Figge Chair, \\ Catholic Studies, University of Iowa, Iowa City, Iowa, USA \\ kristy-nabhan-warren@uiowa.edu \\ Natalie Wigg-Stevenson \\ Ph.D, Associate Professor of Contextual Education and Theology, \\ Emmanuel College, University of Toronto, Toronto, Canada \\ natalie.wigg@utoronto.ca
}

\begin{abstract}
In this article we unpack the significance of the 'crisis in representation' in the field of anthropology for ethnographic approaches to academic theology. The article summarizes and draws connections among other works in this themed issue and presents possibilities for moving forwards with ethnographic theologies that attune carefully to issues of representation. Attending to questions of method, identity, and ethnographic writing, it lifts up some of the diverse and genuinely collaborative approaches to fieldwork that are made possible by the hybrid and complex roles theologians play in relation to the communities and cultures with which they engage.
\end{abstract}

\section{Keywords}

crisis of representation - ethnography - methodology - reflexivity - representation representational politics - theology - ethnographic theology - theological action research

It is an honour for us to co-author this Introduction, and to dig into the rich essays in this special issue of Ecclesial Practices. These essays are in part the 
fruits of a generative 2019 AAR pre-conference workshop (hosted by the "Ecclesial Practices" group) that focused on the ongoing "crisis of representation" in ethnographic approaches to theology. Natalie and our colleague and friend, the anthropologist of religion James Bielo, moderated the event. And Kristy - along with Sarah Dunlop, Kate Lassiter, Sabrina Müller and Todd Whitmore, all featured in this volume - was one of the ten 'table leaders' who ran small-group deep-dives into the issues surrounding the crisis. Participants had the opportunity to hear how other scholars have interpreted, addressed, and responded to the crisis differently, and begin to articulate how they might do so in their own work.

The crisis in representation's genealogy can be traced to two seminal works, both published in 1986: Clifford and Marcus' Writing Culture and Marcus and Fischer's Anthropology as Cultural Critique. ${ }^{1}$ These volumes mapped a significant terrain with regards to representational politics and ethics. Taken together, they have helped lay the methodological and theoretical groundwork for anthropologists' seeking to understand the complexities and challenges of researching with humans within their particular cultural milieus. And the hindsight anthropologists now gained from decades of engagement with both texts offers a treasure trove of wisdom for theologians as they/we seek to engage these issues in a more reflexive way.

Marcus and Fischer determined the crisis to be an "uncertainty about adequate means of describing social realities." ${ }^{2}$ Along with Clifford and Marcus, they named the discomfort, angst and, even vexation that we experience as ethnographers when we work within communities that are not our own. And we both have felt (and, if honest, continue to feel) that vexation! As a young ethnographer in graduate school, I (Kristy) recall poring through these texts at various stages of my program, and I keep returning to them still now. For me and so many other budding ethnographers, these texts were signposts that showed us a way to name what we were seeing, hearing, and experiencing in the field and during the writing process. These texts had not been so foundational to my (Natalie's) work as a theologian, though. We knew them, but we weren't poring over them in the same way as Kristy and her colleagues. It wasn't till after I'd written my first book - and had those lingering feelings of angst that I might have done something wrong when it came to writing up my

1 James Clifford and George E. Marcus, eds., Writing Culture: The Poetics and Politics of Ethnography, 25th anniversary edition / with a foreword by Kim Fortun. (Berkeley, Calif.; University of California Press, 2010); George E. Marcus and Michael M. J. Fischer, Anthropology as Cultural Critique: An Experimental Moment in the Human Sciences (Chicago: University of Chicago Press, 1986).

2 Marcus and Fischer, Anthropology as Cultural Critique, 8. 
field of study - that these questions of representation really came to the fore for me.

Given how much these texts have become a codified diptych for ethnographers across social science and humanities disciplines, we thought it would be helpful for theologians to engage their issues more directly too - hence our AAR workshop's design. We wanted to harness some of this energy that's developed since the late eighties into the aughts, teens and to our contemporary moment among anthropologists to help theologians engage with ethnography's more problematic aspects in a more fully historicized way. In so doing, our hope was to support the creative work theologians are already doing to improve the way we communicate with, and work with, our interlocutors in the field.

Given the significant role that questions of reflexivity have played in ethnographic approaches to theology - the way that the arc of the crisis through the 199os granted us permission to write ourselves into our texts - and how it provided us resources to do so without lapsing into pure solipsism, is of particular interest here. Take, for example, the big splash made by anthropologist of religion, Karen McCarthy Brown's Mama Lola: A Vodou Priestess in Brooklyn. ${ }^{3}$ Praised for its sensitive and fine-grained look into the intricacies of the life of a Haitian refugee and her diasporic community, Mama Lola addressed head-on the politics of representation both in Brown's deeply self-reflexive introduction to the book and interwoven throughout the chapters. Brown herself was troubled by the complicated legacies of Western colonialism, as well as white women's feminism, and in her discussion of ethnographic methods and theories in the introduction, she writes about how the ethnographer and her interlocutors are enmeshed in webs of significance. She troubles the dichotomy between 'etic' and 'emic', outsider and insider, and tells us that the truth is somewhere in between and is messy and complicated.

Katherine Lassiter's "Write Like Wittgenstein on LSD" and Todd Whitmore's "Bringing the Mess That is Life into Theology" in this issue both extend these conversations around self-reflexivity in some risky and important ways. During a period of time when Lassiter lived the tension between her everyday experiences of work and a sweeping spiritual practice that left her feeling like she, "was granted an all-access pass to an ancestral realm," she came to ask herself if she was "just another woman going mad." The journals she kept through both trajectories of experience - the professional and the personal however, helped her uncover the complexities of self-representation when writing up fieldwork. These journals exposed "how the casting of methodology as

3 Karen McCarthy Brown, Mama Lola: A Vodou Priestess in Brooklyn, Comparative Studies in Religion and Society 4 (Berkeley: University of California Press, 1991). 
application of right technique could render epistemological violence to myself if I betrayed my gut." The result is a brilliant foray into "ethnography as therapy, edging towards a potent, transformative auto-theory with the researched other who may themselves being in chaos, crisis or trauma."

Whitmore's piece resonates with this narrative of accompaniment, particularly via his role as a trained addiction recovery coach researching among both persons living with opioid addiction and the family members who seek and struggle to support them. With the power to intervene in the lives of his research participants not simply as participant observer (an ethically fraught enough endeavor when it comes to questions of reflexivity and representation), but also with the expertise, capacity and, even, in some cases mandate to redirect their experience, Whitmore intensifies the ethical problematic at play in any attempt to engage with and write culture.

As with Lassiter's argument, Whitmore also demonstrates how epistemological violence risks coming into play in ethnographic writing. His careful attention to reflexively managing 'self', while engaging with 'other', in fact shifts our theological awareness to the question of theological sources and normativity in important ways. Employing a very telling writing experiment, Whitmore reveals the dangers of choosing the wrong theological sources to support our writing culture. As a result, both Lassiter and Whitmore take us into some fascinating terrain as they navigate questions of reflexivity and theological normativity in previously uncharted ways.

Both authors also live deeply into how the moniker "crisis of representation" in ethnography has attended to the layered and complicated give and take, where relationships are formed, and situations cannot be as contained as they can be within a scientific lab. Ethnography, as Marcus, Clifford, Fischer, and Brown have written, is a method where the researcher and the researched are entangled in multiple ways and, because of these entanglements, ethnography should be treated like an artform and as a form of human relationship. Indeed, the authors in this special issue demonstrate, as Brown so effectively argued, "When the lines long drawn in anthropology between participant-observer and informant break down, then the only truth is the one in between; and anthropology becomes something closer to a social art form, open to both aesthetic and moral judgment. The situation is riskier, but it does bring intellectual labour and life into closer relation."

Sarah Dunlop and Jon Marlow's piece, "Answers on a Postcard," provides an anchor within this selection of articles for those who want to think more carefully about the role actual artforms can play in doing the art of ethnography.

4 Karen McCarthy Brown, Mama Lola, 12. 
Using photo elicitation, Dunlop and Marlow seek to evoke affective responses in their research participants that could not be as effectively produced by observation or interviewing alone. In this way, they're able to "generate theological knowledge that may have been previously unknown, even to participants themselves."

Here, issues of representation in the field shift away from mere verbal language towards images. This furthermore impacts representation in their written text as interlocutors are invited to participate in data interpretation as well. By engaging ethnography as a shared "creative practice" with the research participants, Dunlop and Marlow empower congregants to treat their own ministry and missional practices as likewise creative. The impact of the work is felt not only in the written texts, but also in the changed activity on the ground as, of course, participatory action research methods endeavor to do.

Dunlop and Marlow's work exemplifies one type of participatory action research - an arts-based approach that seeks to elicit creative response, while Sabrina Müller and Patrick Todjeras' exemplifies another. Drawing on practices of citizen science, Müller and Todjeras empower their research community to generate, discuss, interpret, evaluate and disseminate their data together. Using this form of "emancipatory research, which aims to promote community ownership" of the process, the authors were also able to effect a type of individual and collective empowerment among their participants. Given that the project's scope related specifically to how to empower laity to become "competent partners in church leadership," their collaborative method begins to implement the very practices that their research sought to develop.

Müller and Todjeras' article offers the most profoundly democratized approach to scholarship among those gathered here, truly pushing the envelope of the crisis in terms of collaborative field-based approaches to community engagement and knowledge production. As with all the authors in this volume, attention to issues of representation infuses the work with a liberatory edge and, ultimately, a deep questioning of how ethnographic approaches to theological research might serve the kinds of Christian practice they study.

Of course, like Brown, other feminist ethnographers also critically expanded the Writing Culture conversation in ways that attempted to dismantle a male, Western, colonialist, heteronormed, White gaze in similarly liberative ways. ${ }^{5}$

5 The anthropologist Ellen Lewin has been a pioneer in feminist anthropology and her single-authored as well as collaborative works have helped pave the way for decolonized, de-heteronormative, and less white anthropologies. See: Lewin, Recognizing Ourselves (Columbia University Press, 1998); Feminist Anthropology: A Reader (Wiley-Blackwell, 20o6); Gay Fatherhood: Narratives of Family and Citizenship in America (University of Chicago Press, 
Furthermore, to apply a current 2021 lexicon to the 8 os and gos writings, the anthropologists who tackled the problematics of ethnographic method, theory, and writing, paved the way for new generations who have been on a quest for more "woke" ethnographies. ${ }^{6}$ But what distinguishes the theological essays in this collection is that their authors are coming at the crisis of representation wearing many hats: they're 'everyday' Christians, professionally trained theologians, ordained ministers and laypersons, activists, and social care providers. In many ways, these authors already embody complex belonging to their fields of study, long before having entered them. As a result, they're able to explore truly collaborative, interactive, participatory-action oriented, and even therapeutic ways of doing/performing/enacting ethnography. The theoretically and theologically engaged and highly concrete examples from their fieldwork offers the rest of us insights for how to approach these questions in our own research in some fresh and generative ways.

2009); and co-edited with Leni Silverstein, Mapping Feminist Anthropology of the 21st Century (Rutgers University Press, 2016). Lewin's most recent book, Filled with the Spirit: Sexuality, Gender, and Radical Inclusivity at a Black Pentecostal Church Coalition (University of Chicago Press, 2018) is a superb ethnography of a radically inclusive Black Pentecostal community in which Lewin's deep commitment to feminist ethnography and a re-centering of dynamics between interlocutors and the ethnographer really come in to play.

6 The 1991 publication of Karen Brown's Mama Lola ushered in an ethnographic turn in the study of religion. Religious Studies ethnographies in particular began emphasizing deep, qualitative ethnography interspersed with self-reflexivity on the part of the author. This new wave of religious studies ethnographers was also interdisciplinary in their approach to the study of religion, and drew on ethnic and race studies, feminist theory as well as migration histories that enriched their work. These post-1991 religious studies ethnographies that were influenced by Brown's work include Lila Anu-Lughod, Writing Women's Worlds: Bedouin Stories (University of California Press, 1993); Marie Griffith, God's Daughters: Evangelical Women and the Power of Submission (University of California Press, 1997); Thomas Tweed, Our Lady of the Exile: Diasporic Religion at a Cuban National Shrine in Miami (Oxford University Press, 1997); Kristy Nabhan-Warren, The Virgin of El Barrio: Marian Apparitions, Catholic Evangelizing, and Mexican American Activism (NYU Press, 2005); Elaine A. Peña, (University of California Press, 2011), and most recently, Elizabeth Pérez, Religion in the Kitchen: Cooking, Tasting, and the Making of Black Atlantic Traditions (NYU Press, 2016). Finally, I am the series editor of Where Religion Lives, a book series with The University of North Carolina Press. Executive Editor Elaine Maisner and I developed this series as a home for innovative ethnographies of religion. We work closely with authors to develop authorial voices where self-reflexivity connects with rigorous fieldwork and writing. Karen Brown was the inspiration for Where Religion Lives and it is our hope that the series is home to current and future ethnographies of religion that address and take seriously the relationships formed and dynamics of power that exist between the researcher and her interlocutors. 